\title{
LIBERAÇÃO DA DORMÊNCIA EM ARROZ VERMELHO: AÇÕES DO PERÍODO E DA TEMPERATURA DE ARMAZENAMENTO E DA INTEGRIDADE FÍSICA DAS SEMENTES
}

\section{DORMANCY BREAKING IN RED RICE: TEMPERATURE AND STORAGE PERIOD AND SEED PHYSICAL INTEGRITY ACTIONS}

\author{
Dirceu AGOSTINETTO ${ }^{1}$ -
Nilson Gilberto FLECK \\ Emerson Luiz Nunes COSTA ${ }^{3}$ \\ Ribas Antonio VIDAL ${ }^{2}$ \\ Aldo MEROTTO JÚNIOR ${ }^{4}$
}

\begin{abstract}
RESUMO
A ocorrência de baixa temperatura na estação fria e os danos físicos impostos às sementes presentes no solo são fatores que podem influenciar a liberação da dormência em arroz vermelho. Dois experimentos foram conduzidos com o objetivo de avaliar os efeitos do período e da temperatura de armazenamento e da integridade física das sementes de arroz vermelho no processo de liberação da dormência. No primeiro, os tratamentos constaram de três temperaturas de armazenamento das sementes $\left(-10,10\right.$ e $\left.20^{\circ} \mathrm{C}\right)$, duas temperaturas de germinação $(20$ e $30^{\circ} \mathrm{C}$ ), dois estados de integridade das sementes de arroz vermelho (intactas e descascadas) e quatro períodos de realização do teste de germinação $(14,28,42$ e 56 dias após a colheita). O segundo experimento testou três estados de integridade das sementes (intactas, descascadas e perfuradas) e foi realizado em dois períodos ( 8 e 110 dias após a colheita). O delineamento experimental utilizado em ambos os experimentos foi o completamente casualizado, com cinco repetições. A variável avaliada foi a percentagem de germinação de sementes. Os resultados obtidos permitem concluir que baixas temperaturas de armazenamento das sementes mantêm a dormência pós-maturação, sendo que a dormência diminui com o aumento do período de armazenamento em temperatura de $20^{\circ} \mathrm{C}$.
\end{abstract}

Palavras-chave: Oryza sativa, banco de sementes, germinação.

\begin{abstract}
Occurrence of low temperature during the cold season and physical damage suffered by seeds stored into soil are factors that may affect dormancy breaking in red rice seeds. Two experiments were carried out with the aim to evaluate the effects of storage period and temperature and physical integrity of red rice seeds on the process of dormancy breaking. In the first one, treatments consisted of three seed storage temperatures $\left(-10,10\right.$, and $\left.20^{\circ} \mathrm{C}\right)$, two germination temperatures $\left(20\right.$ and $\left.30^{\circ} \mathrm{C}\right)$, two seed integrity conditions (intact and dehulled), and four germination times after seed harvesting $(14,28,42$, and 56 days). The second experiment tested three integrity conditions of the seeds (intact, dehulled, and bored) and was performed at two periods (8 and 110 days after seed harvesting). The experimental design used in both trials was a completely randomized one, with five replicates. Variable evaluated was seed germination percentage. Results obtained allow to conclude that maintenance of low temperature during seed storage extends post-ripening dormancy, and that dormancy lessens with increasing of seed storage period under temperature of $20^{\circ} \mathrm{C}$.
\end{abstract}

\footnotetext{
1 Engenheiro Agrônomo, Aluno do Programa de Pós-Graduação em Fitotecnia da Faculdade de Agronomia da Universidade Federal do Rio Grande do Sul, Caixa Postal 776, CEP 91501-970, Porto Alegre, RS. E-mail: dirceua@vortex.ufrgs.br $\equiv$ Autor para correspondência.

2 Engenheiro Agrônomo, Doutor, Universidade Federal do Rio Grande do Sul, Professor, Departamento de Plantas de Lavoura, Bolsista do CNPq.

3 Aluno do Curso de Agronomia da Universidade Federal do Rio Grande do Sul, Bolsista do CNPq.

${ }^{4}$ Engenheiro Agrônomo, Doutor, Universidade Federal do Rio Grande do Sul, Professor, Departamento de Plantas de Lavoura.
} 
Key words: Oryza sativa, seedbank, germination.

INTRODUÇÃO

O arroz é o cereal mais cultivado no mundo. No Rio Grande do Sul, posiciona-se entre as principais culturas, ocupando área aproximada de um milhão de hectares [8]. A produtividade média de arroz no Estado cresceu nas últimas duas décadas, atingindo patamar de 5,1 tha ${ }^{-1}$, o que decorre, especialmente, da utilização de cultivares com alto potencial produtivo e da adoção de tecnologias modernas. No entanto, essa produtividade está bem aquém do potencial obtido nas áreas experimentais. Esse fato deve-se, basicamente, ao controle insatisfatório das plantas daninhas. Entre as espécies daninhas que infestam as lavouras do Estado, destaca-se o arroz vermelho como aquela que mais limita $\mathrm{o}$ aumento da produtividade da cultura, sendo considerado como a espécie infestante que ocasiona os maiores prejuízos [17].

$\mathrm{O}$ arroz vermelho pertence à mesma espécie botânica do arroz cultivado (Oryza sativa L.) e, como apresenta características de planta muito similares ao cultivado, seu controle torna-se difícil pelos métodos convencionais, elevando o custo de produção e diminuindo o valor comercial das áreas infestadas. Apresenta porte alto, folhas verdeclaras, decumbentes e pilosas, colmos finos, alta capacidade de afilhamento e sementes com pericarpo avermelhado, aristas longas, altas taxas de dormência e debulha natural [9].

A dormência das sementes de espécies infestantes e a sua persistência no solo são formas de dispersão no tempo que, geralmente, combinam condições ambientais com fatores intrínsecos às sementes. Nesse sentido, a dormência pode ser considerada um fator agravante no controle dessas espécies e na adoção de práticas de manejo mais adequadas.

As sementes de arroz vermelho, geralmente, apresentam grau de dormência variável, de acordo com os diferentes biótipos, e suas causas não estão bem definidas. As técnicas utilizadas para a superação da dormência apresentam resultados diferenciados. De acordo com Menezes et al. [11], não houve diferença significativa na germinação entre as sementes de biótipos com casca preta ou casca amarelo-palha. Porém, os biótipos de grãos "longo-finos" e grãos "curtos" apresentaram comportamentos distintos. A germinação dos biótipos de arroz vermelho aumenta e a dormência decresce com a ampliação do tempo de armazenamento das sementes sob condições de baixas temperaturas e umidades relativas [14]. Geralmente a superação da dormência é mais rápida em sementes colhidas com menor grau de umidade.

A disponibilidade térmica interfere na dormência. $O$ efeito do frio na superação da dormência é comum em espécies de clima temperado [1]. As oscilações de temperatura que se verificam no Rio Grande do Sul, no período outono/inverno e no início da primavera e o dano mecânico provocado pelos implementos agrícolas nas sementes de arroz vermelho que se encontram no solo, são fatores que podem influenciar o nível de dormência das sementes. A determinação dos fatores envolvidos na liberação da dormência possibilita a elaboração de estratégias de manejo que visem diminuir o banco de sementes e as infestações futuras. Dessa forma, o presente trabalho objetivou avaliar os efeitos do período e da temperatura de armazenamento e da integridade física das sementes de arroz vermelho no processo de liberação da dormência.

\section{METODOLOGIA}

As atividades de pesquisa, compreendendo dois experimentos, foram desenvolvidas em laboratório no Departamento de Plantas de Lavoura da Faculdade de Agronomia da UFRGS. Panículas de arroz vermelho foram colhidas aleatoriamente na área experimental da Estação Experimental do Arroz, do Instituto Rio-Grandense do Arroz, no município de Cachoeirinha, RS. A colheita foi realizada no mês de abril de 1998. Após a determinação do grau de umidade das sementes, procedeu-se a uniformização para $13 \%$ por secagem em estufa com circulação forçada de ar. Posteriormente, as sementes foram acondicionadas em frascos de vidro. Esses foram fechados e envoltos com papel alumínio e armazenados. Nesse experimento as estruturas externas pálea, lema e glumas, que recobrem o endosperma e o embrião (pericarpo), foram consideradas, em seu conjunto, como a casca do grão (fruto) de arroz.

O delineamento experimental utilizado nos experimentos foi o completamente casualizado em esquema fatorial, com cinco repetições. No primeiro experimento os tratamentos constaram de três temperaturas de armazenamento $\left(-10,10\right.$ e $\left.20^{\circ} \mathrm{C}\right)$, duas temperaturas de germinação $\left(20\right.$ e $\left.30^{\circ} \mathrm{C}\right)$, dois estados de integridade física das sementes (intactas e descascadas) e quatro períodos de armazenamento $(14,28,42$ e 56 dias após a colheita). O segundo experimento foi conduzido em dois períodos de armazenamento (8 e 110 dias após a colheita) e com três estados de integridade das sementes de arroz vermelho (intactas, descascadas e perfuradas). Nos tratamentos em que as sementes foram descascadas, a remoção da casca foi realizada manualmente. Para o tratamento em que o casca das sementes foi perfurada, utilizou-se agulha histológica, realizando-se três perfurações em espaços eqüidistantes e no sentido longitudinal, em cada lado das sementes. Para uniformizar a profundidade das perfurações, utilizou-se como critério o contato da agulha com o pericarpo das sementes.

Como substrato para os testes utilizou-se papel de germinação tipo germitest e a metodologia seguiu as recomendações das Regras para Análise de Sementes [2], diferindo apenas quanto aos números de sementes e repetições $(5$ x 50 em vez 
de 4 x 100). Durante os períodos de realização dos testes os germinadores foram mantidos sob temperaturas constantes de 20 e $30^{\circ} \mathrm{C}$, no primeiro experimento, e $30^{\circ} \mathrm{C}$, no segundo experimento. A avaliação de germinação foi realizada 10 dias após a instalação, em ambos os experimentos, considerando-se germinada a semente que emitisse no mínimo $0,5 \mathrm{~cm}$ da raiz primária. Os dados coletados durante a condução do experimento foram previamente transformados para arco-seno $\sqrt{ }(x+1)$ e então submetidos à análise de variância pela estatística $\mathrm{F}$ e a comparação de médias foi feita pelo teste de Duncan, a $1 \%$ de probabilidade.

\section{RESULTADOS E DISCUSSÃO}

Os resultados obtidos para germinação, em função dos períodos e das temperaturas de armazenamento, são apresentados na Figura 1. As sementes armazenadas à temperatura de $10^{\circ} \mathrm{C}$ mantiveram a dormência pós-colheita pelo menos até 56 dias após o início do armazenamento. Para as sementes armazenadas a $10^{\circ} \mathrm{C}$ verificou-se aumento da germinação nos últimos períodos de realização do teste, comparativamente aos primeiros. Já, quando a temperatura de armazenamento foi $20^{\circ} \mathrm{C}$, observou-se gradativo aumento na germinação



desde o início.

\begin{abstract}
Barras superescritas por letras maiúsculas comparam períodos de armazenamento dentro de temperaturas de armazenamento; superescritas por letras minúsculas comparam temperaturas dentro de cada período, quando idênticas não diferem significativamente entre si pelo teste de Duncan, a $1 \%$ de probabilidade
\end{abstract}

FIGURA 1 - Percentagem de germinação de sementes de arroz vermelho em função dos períodos e das temperaturas de armazenamento. Faculdade de Agronomia/UFRGS, Porto Alegre, RS, 1998

Comparando-se as diferentes temperaturas de armazenamento nos vários períodos de realização do teste, observou-se que a temperatura de $20^{\circ} \mathrm{C}$ foi a que proporcionou maior liberação de dormência das sementes do arroz vermelho. De modo genérico, as demais temperaturas de armazenamento não proporcionaram diferenças significativas. Ainda, com relação às temperaturas de armazenamento, observou-se (Figura 2) que sementes armazenadas a $20^{\circ} \mathrm{C}$ apresentaram germinação superior à das demais temperaturas testadas. Deste modo, os dados sugerem que a ocorrência de temperaturas amenas na estação fria $\left(20\right.$ a $25^{\circ} \mathrm{C}$ ) pode apressar a superação da dormência em sementes de arroz vermelho. Quanto à integridade física das sementes, verificou-se maior percentual de germinação das sementes descascadas em relação às intactas, independentemente das temperaturas de armazenamento. Esses resultados evidenciam a possível presença de inibidor(es) químico(s) da germinação na casca ou ação de impermeabilidade desta à entrada de água ou a trocas gasosas, já que a germinação das sementes descascadas superou a das sementes intactas em todas as temperaturas usadas.

Os dados obtidos neste trabalho estão de acordo com os observados por Cohn e Hughes [4]. Esses autores verificaram que sementes intactas de arroz vermelho, armazenadas a $-15^{\circ} \mathrm{C}$, após secagem à temperatura ambiente, permaneceram dormentes após um ano de armazenamento. Quando as sementes armazenadas a $-15^{\circ} \mathrm{C}$ foram descascadas e postas para germinar, os autores observaram variação de 3 a $12 \%$ na germinação. A variação pode ser devida aos danos mecânicos provocados durante o processo de remoção da casca. Os autores indicam que a baixa percentagem de germinação demonstra alta estabilidade da dormência quando as sementes são armazenadas à baixa temperatura. $\mathrm{E}$ mais, a estocagem de sementes de arroz vermelho a $5^{\circ} \mathrm{C}$ atrasou a liberação da dormência, sendo a germinação inferior a $5 \%$ durante período de três meses após o início do 
armazenamento. Os dados obtidos pelos autores enfatizam a importância da casca na preservação da dormência e demonstram variação na resposta das sementes quando armazenadas em diferentes temperaturas.

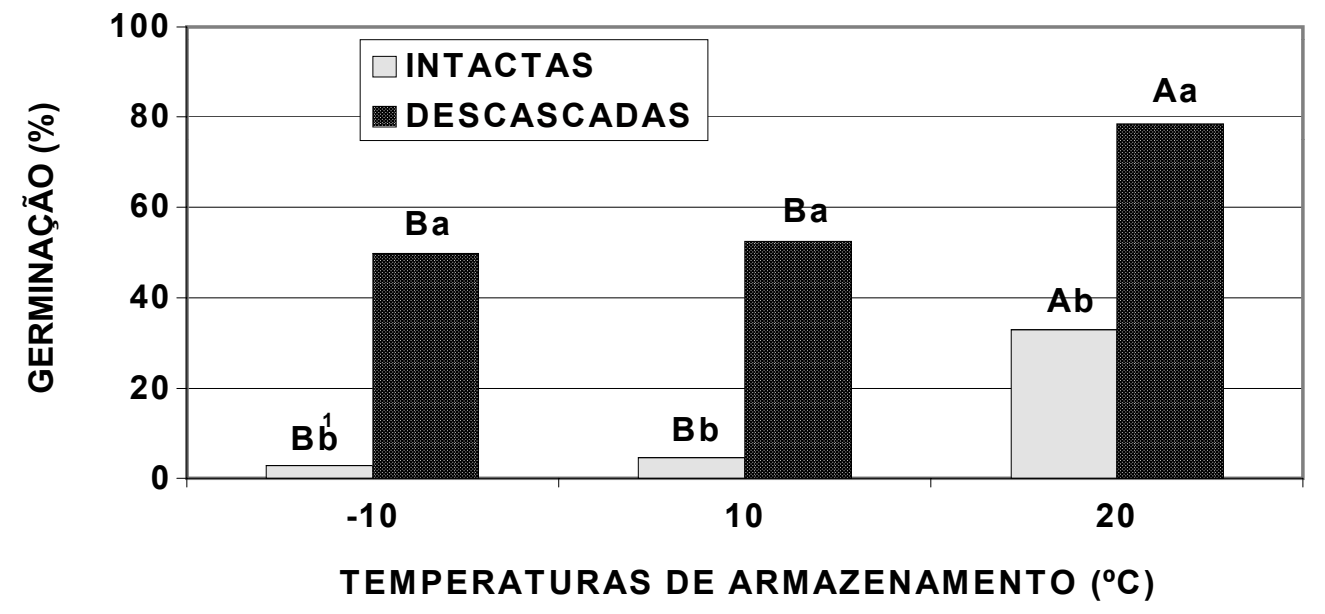

1 Barras superescritas por letras maiúsculas comparam temperaturas de armazenamento dentro do fator estado das sementes; superescritas por letras minúsculas comparam estados dentro de cada temperatura, e quando idênticas não diferem significativamente entre si pelo teste de Duncan, a $1 \%$ de probabilidade

FIGURA 2 - Percentagem de germinação de sementes de arroz vermelho em função das temperaturas de armazenamento e do estado das sementes, Faculdade de Agronomia/UFRGS, Porto Alegre, RS, 1998

A dormência em sementes de arroz cultivado persiste apenas por algumas semanas, após serem submetidas às condições normais de armazenamento [5]. Porém, se as sementes forem armazenadas a $7^{\circ} \mathrm{C}$, a dormência pode persistir por mais de um ano. A dormência é induzida durante o desenvolvimento da semente, sendo influenciada por luz, temperatura e umidade que as plantas recebem no período de formação da mesma e também por aspectos nutricionais da planta [18]. O autor relata que a indução da dormência pode ser causada por mudanças hormonais, formação e acumulação de substâncias que impedem a germinação e, ainda, pela impermeabilidade da casca e por presença de condições anaeróbicas à semente. De acordo com o autor [18], dos fatores do ambiente que induzem a dormência, o mais importante em sementes de arroz é a temperatura.

A comparação isolada dos períodos de armazenamento demonstrou incremento da germinação nos dois últimos períodos de realização do teste em relação aos dois primeiros (Figura 3). Foi exceção o tratamento com sementes descascadas submetidas à temperatura de $30^{\circ} \mathrm{C}$, em que a percentagem de germinação posicionou-se entre 75 e $84 \%$. Independente da temperatura a que foram submetidas as sementes e do período de armazenamento, a germinação das sementes descascadas sempre superou a germinação das sementes intactas. Percentualmente, essas diferenças foram maiores quando as sementes foram submetidas à temperatura de $30^{\circ} \mathrm{C}$ que quando mantidas a $20^{\circ} \mathrm{C}$ (Figura 3 ). Em todos os períodos de armazenamento verificou-se que, dentro de cada estado físico das sementes, ocorreu maior germinação à temperatura de $30^{\circ} \mathrm{C}$ que a $20^{\circ} \mathrm{C}$. Essas diferenças foram maiores nas sementes descascadas, em comparação às sementes intactas.

$\mathrm{Na}$ literatura existe controvérsia a respeito da importância da casca na dormência de sementes. Sementes de Avena fatua apresentaram resposta variável à remoção da casca [16]. A magnitude da germinação de sementes descascadas de arroz também variou entre cultivares [13]. Especula-se que estas diferenças possam ser de origem genética ou devida aos danos causados às sementes durante o processo de remoção da casca. Miyoshi et al. [12] observaram que a resposta de sementes de cultivares de arroz à remoção da casca variou de acordo com o grupo de origem (índica ou japônica). Os autores verificaram que a remoção da casca estimulou a germinação de sementes de cultivares do grupo índica e inibiu as do grupo japônica. Já os dados obtidos por Cohn e Hughes [4] demonstraram que a remoção da casca resultou em elevação na percentagem de germinação, independentemente da temperatura de armazenamento $(-15,5,20$ ou $\left.30^{\circ} \mathrm{C}\right)$.

A remoção e a perfuração da casca de sementes de arroz vermelho promoveu aumento da germinação, comparativamente às sementes intactas, quando o teste foi realizado oito dias após a colheita (Figura 4). Já aos 110 dias após a 


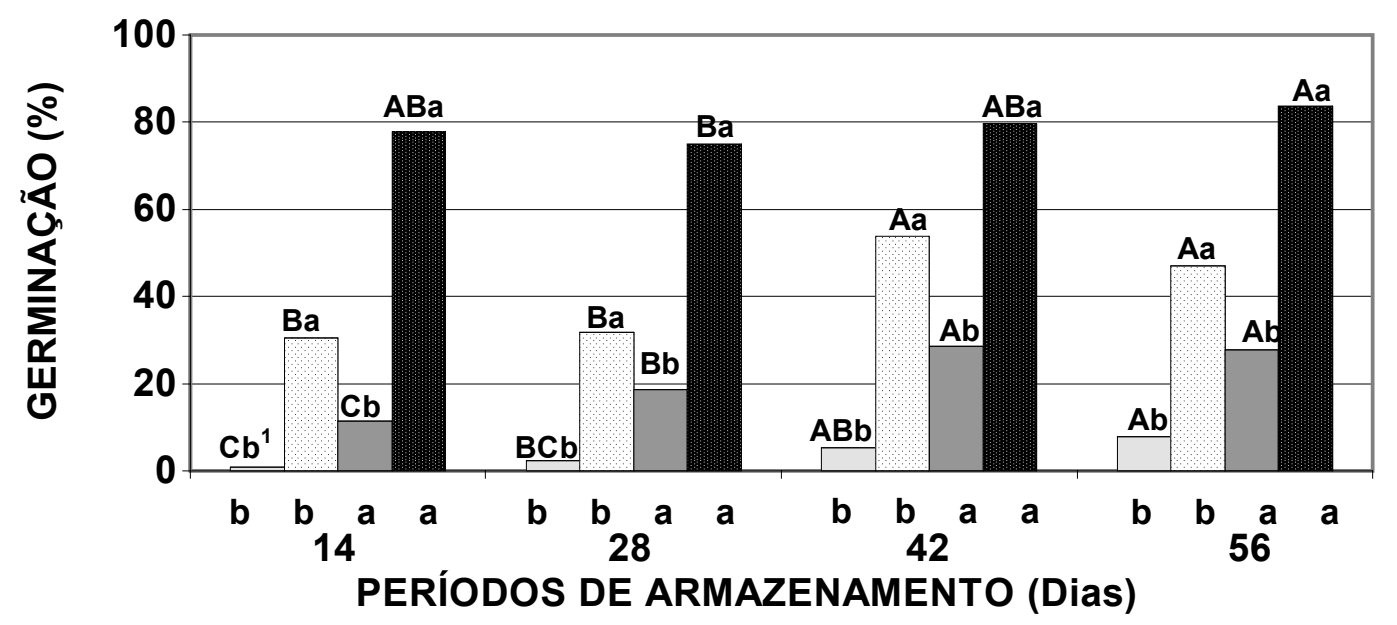

$\square$ INTACTAS $20^{\circ} \mathrm{C} \square$ DESCASCADAS $20^{\circ} \mathrm{C} \square$ INTACTAS $30^{\circ} \mathrm{C}$ DESCASCADAS $30^{\circ} \mathrm{C}$

1 Barras superescritas por letra maiúsculas comparam períodos de armazenamento dentro dos fatores temperatura de germinação e estado das sementes; superescritas por letras minúsculas comparam estados dentro dos fatores períodos de armazenamento e temperatura de germinação; subescritas por letras minúsculas comparam temperaturas de germinação dentro dos fatores período de armazenamento e estado, e quando idênticas não diferem significativamente entre si pelo teste de Duncan, a $1 \%$ de probabilidade

FIGURA 3 - Percentagem de germinação de sementes de arroz vermelho em função dos períodos de armazenamento, das temperaturas de germinação e dos estados das sementes, Faculdade de Agronomia/UFRGS, Porto Alegre, RS, 1998

colheita, observou-se maior germinação das sementes descascadas em relação às perfuradas, no entanto, ambas não diferiram das sementes mantidas intactas. A menor percentagem de germinação das sementes perfuradas deveu-se, provavelmente, à infestação de patógenos, provocada pelo manuseio das sementes. $O$ incremento na germinação de sementes intactas, ocorrido com 110 dias, evidencia a presença de inibidor(es) da germinação na casca que se degrada $(m)$ durante o período de armazenamento. Por outro lado, a perfuração das sementes favoreceu a entrada de água e oxigênio, lixiviando os inibidores e aumentando a germinação. Porém, estes não são os únicos fatores envolvidos na inibição da germinação, visto que a maior germinação obtida aos oito dias foi de $22 \%$ (sementes descascadas).

Os resultados obtidos assemelham-se aos observados por Santos et al. [15] que verificaram maior germinação de sementes de arroz vermelho, comparado a quatro variedades de arroz cultivado, quando ambas foram descascadas. Por sua vez, Larinde [10], trabalhando com cinco cultivares de arroz, observou que a ruptura do pericarpo ao longo da periferia do embrião induziu as sementes à germinação. $\mathrm{O}$ autor concluiu que a dormência aparentemente era devida à impermeabilidade do complexo casca/pericarpo ao oxigênio, ao invés da presença de inibidores na casca. Também Felipe e Polo [6] observaram que a dormência ocasionada pela impermeabilidade da casca à entrada de água é fato comum em sementes de espécies invasoras.
Os autores salientam que este processo se constitui em importante mecanismo de sobrevivência, pelo qual as sementes podem permanecer dormentes por longo período de tempo. Além disso, a resistência que a casca oferece ao crescimento do embrião pode prejudicar o processo de germinação.

Por outro lado, Fraga [7] relatou que a dormência parece estar relacionada com os níveis endógenos de $\mathrm{CO}_{2}$ ou com a presença de inibidores que interferem na penetração de oxigênio. O consumo de oxigênio pela casca, em algumas espécies, é atribuído à oxidação de vários compostos fenólicos, tais como floridizin, ácido clorogênico e ácido paracumaril-químico, reconhecidamente presentes na casca das sementes [3]. Embora numerosos estudos tenham sido realizados, verifica-se que em sementes de arroz, diversos fatores estão implicados na dormência, os quais podem manifestar-se combinados ou isolados, dificultando a definição de qual fator seja o principal responsável pela dormência.

\section{CONCLUSÕES}

Os resultados obtidos permitem concluir que sementes armazenadas em baixas temperaturas mantêm a dormência pós-colheita durante período mais longo e a dormência é liberada mais cedo quando as sementes são armazenadas em temperatura de $20^{\circ} \mathrm{C}$ durante período mais longo. 


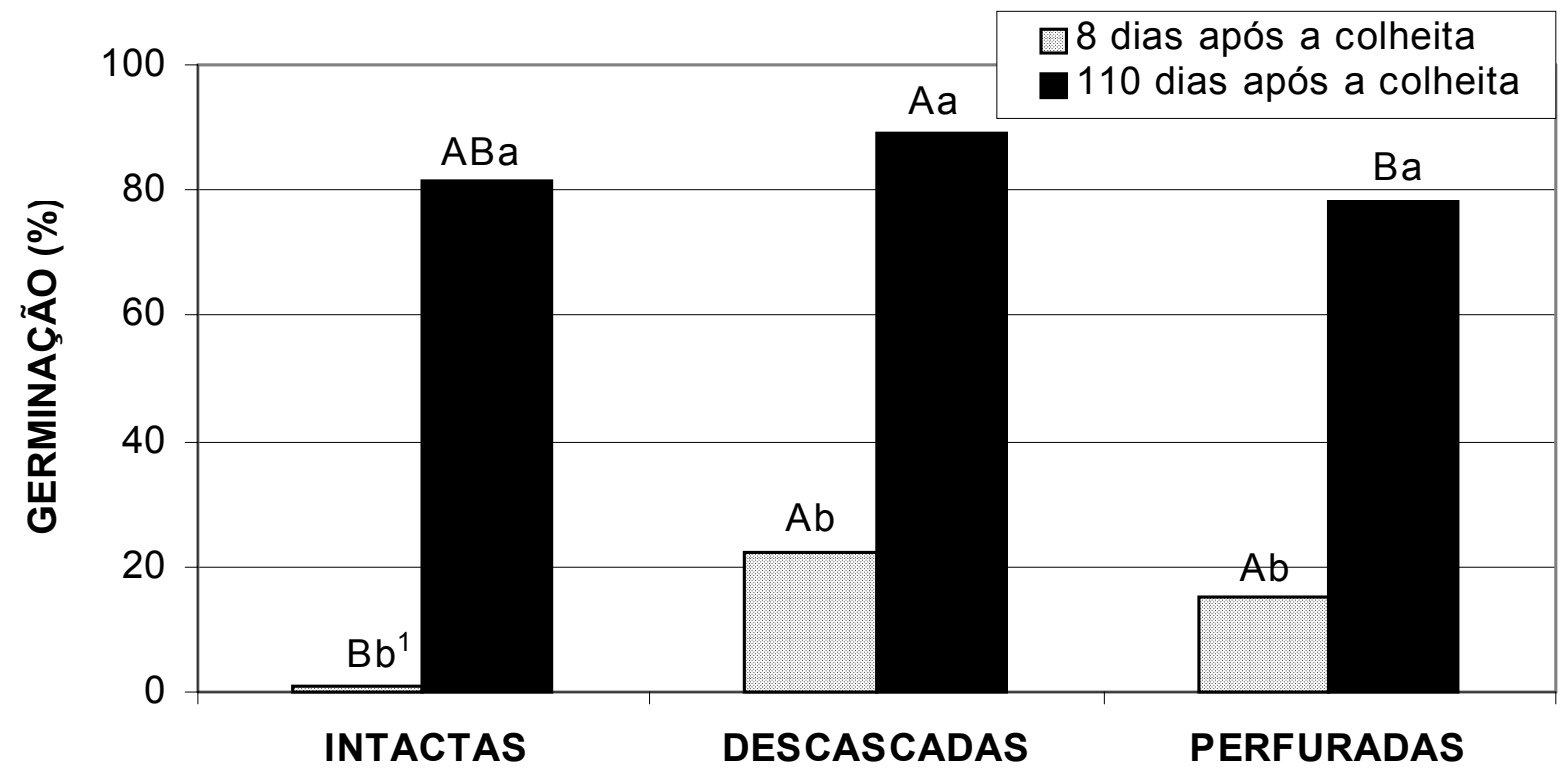

1 Barras superescritas por letras maiúsculas comparam estados das sementes dentro de cada período de armazenamento e por letras minúsculas os períodos de armazenamento dentro de cada estado das sementes, e quando idênticas não diferem significativamente entre si pelo teste de Duncan, a $1 \%$ de probabilidade.

FIGURA 4 - Percentagem de sementes germinadas de arroz vermelho em função dos estados das sementes e dos períodos de armazenamento, Faculdade de Agronomia/UFRGS, Porto Alegre, RS, 1998

\section{REFERÊNCIAS}

[1] EWLEY, J. D.; BLACK, M. Physiology and biochemistry of seeds in relation to germination. Berlin: Springer-Verlog, 1982. 375 p. (v.2)

[2] BRASIL. Ministério da Agricultura e Reforma Agrária. Regras para análise de sementes. Brasília: MARA. CLAV, 1992. $365 \mathrm{p}$.

[3] CíCERO, S. M. Dormência de sementes. In CÍCERO, S. M.; MARCOS FILHO, J.; SILVA, W. R. (Eds.) Primeira semana de atualização em produção de sementes. Piracicaba: Fundação Cargill, 1986. p. 41-73.

[4] COHN, M. A; HUGHES, J. A. Seed dormancy in red rice (Oryza sativa): I. Effect of temperature on dryafterripening. Weed Science, Champaign, v.29, n.4 p. 402-404, 1981

[5] DELOUCHE, J. C. Seed dormancy in gramineae. Mississippi: [s/editor], 1960. $20 \mathrm{p}$

[6] FELIPE, G. M.; POLO, M. Germinação de ervas invasoras: efeito da luz e escarificação. Revista Brasileira de Botânica, São Paulo, v.6, p. 55-60, 1983.

[7] FRAGA, A. C. Dormência de sementes. Informe Agropecuário, Belo Horizonte, v.8, n.91, p.62-64, 1982.

[8] IBGE. Anuário estatístico do Brasil, Rio de Janeiro, v.56, p. 3-56, 1996

[9] KWON, S. L.; SMITH JUNIOR, R. J.; TALBERT, R. E. Comparative growth and development of red rice (Oryza sativa) and rice (O. sativa). Weed Technology, Champaign, v.40, n.1, p. 57-62, 1992.

[10]LARINDE, M. A. Seed maturation, development and release of dormancy in red rice. Mississipi, 1979. $59 \mathrm{f}$. Dissertação (M. Sc. Seed Technology) Mississippi State University.

[11]MENEZES, V. G.; SILVA, P. R. F.; DELATORRE, C. A.; CARMONA, R.; REZERA, F.; MARIOT, C.H. Dormência em sementes de biótipos de arroz vermelho. In:
REUNIÃO DA CULTURA DO ARROZ IRRIGADO, 21. 1995, Porto Alegre. Anais. Porto Alegre: IRGA, 1995. p. 268-271.

[12]MIYOSHI, K.; SATO, T.; TAKAHASHI, N. Differences in the effects of seeds of indica and japonica rice (Oryza sativa L.). Annals of Botany, London, v.77, n.6, p. 599-604, 1996.

[13]NAVERSERO, E. P.; BAUN, L. C.; JULIANO, B. O. Grain dormancy, peroxidase activity and oxygen uptake in Oryza sativa. Phytochemistry, New York, v.14, n.8, p. 1899-1902, 1975

[14]NOLDIN, J. A.; CHANDLER, J. M. Viabilidade e dormência de sementes de ecótipos de arroz vermelho em função do grau de umidade na colheita. In: REUNIÃO DA CULTURA DO ARROZ IRRIGADO, 22., 1997, Balneário Camboriú. Anais. Itajaí: EPAGRI, 1997. p. 443-446.

[15]SANTOS, D. S. B.; RIBEIRO, A. S.; FERNANDES, H. S.; GALLI, J. Influência do descasque na germinação de arroz (Oryza sativa L.) daninho e cultivado, no Rio Grande do Sul. In: REUNIÃO DO CULTURA DO ARROZ IRRIGADO, 21.,Porto Alegre, 1995. Anais. Porto Alegre: IRGA, 1995. p. 286-271.

[16]SIMPSON, G. M. Metabolic regulation of dormancy in seeds - a case history of the wild oat (Avena fatua). In: CLUTTER, M. E. (Ed.) Dormancy and development. New York: Academic Press, 1978. p. 167-220.

[17]SOUZA, P. R.; FISCHER, M.M. Arroz vermelho: danos causados à lavoura gaúcha. Lavoura Arrozeira, Porto Alegre, v.39, n.368, p. 19-20,, 1986.

[18]TAKAHASHI, N. Physiology of dormancy. In: MATSUO, T.; KURAMAZAWA, K.; ISHII, R.; ISHIHARA, K.; HIRATA, H. Science of the rice plant. Tokyo: Food and Agriculture Policy Research Center, 1995.

p. $45-65$.

(v.2) 
Recebido para publicação em 16 SET 1999 [SA 007/1999] Aceito para publicação em 19 FEV 2001 